\title{
HORTA UM INSTRUMENTO PEDAGÓGICO NA ESCOLA MUNICIPAL JARDIM DAS FLORES: UMA ALIADA NA EDUCAÇÃO AMBIENTAL
}

\author{
Jonis Franklin Leite dos Santos \\ Escola Municipal Jardim das Flores / Alta Floresta - MT \\ jonisfranklin@hotmail.com \\ Denise Borkenhagen dos Santos \\ Escola Municipal Jardim das Flores / Alta Floresta - MT \\ jonisfranklin@hotmail.com
}

\section{Resumo}

O projeto foi realizado com aos alunos do ensino fundamental da Escola Municipal Jardim das Flores, localizada em Alta Floresta - MT, no período de março a dezembro de 2011. Teve por objetivo mostrar a importância do alimento saudável no cultivo de hortaliças e reaproveitamento de resíduos orgânicos domiciliar na produção de húmus através da compostagem. Para o plantio das hortaliças e leguminosas foram realizada entrevista com uma amostra representativa de 100 estudantes do ensino fundamental, escolhido pela coordenação da escola, dando preferência no plantio, aquelas que obtiveram maior aceitabilidade pelos entrevistados. As de maior destaque foram alface, couve e almeirão, e as de menor são a rúcula e o coentro. As verduras desejadas com maior frequência na alimentação domiciliar foram à alface, repolho e almeirão. As de menor indicação são a cebolinha e a rúcula. $90 \%$ dos educando que participaram do projeto, estão praticando a utilização dos resíduos domésticos e outros resíduos na confecção da compostagem domiciliar.

Palavras-chave: Compostagem. Fertilizante. Hortaliças.

\section{HORTA TEACHING AN INSTRUMENT IN MUNICIPAL SCHOOL GARDEN FLOWERS: AN ALLY IN ENVIRONMENTAL EDUCATION}

\begin{abstract}
The Project was conducted with the elementary students of the City School Garden of Flowers, located in Alta Floresta - MT, from March to December 2011. Aimed to show the importance of healthy food to grow vegetables and recycling of household organic waste in the production of humus through composting. For the planting of vegetables and legumes were interviewing a representative sample of 100 elementary school students, chosen for coordinating the school, giving preference to plant those that had higher acceptability by respondents. The most prominent were lettuce, kale and endive, and arugula are smaller and
\end{abstract}


coriander. The vegetables most often desired in the home were feeding lettuce, cabbage and chicory. The slightest indicate of chives and are Arugula. 90\% of leamers who participated in the project, are practicing the use of household waste and other waste in the manufacture of home composting.

Keywords: Composting. Fertilizer. Vegetables.

\section{INTRODUÇÃO}

A educação ambiental deve buscar valores que conduzam a uma convivência harmoniosa com o ambiente e as demais espécies que habitam o planeta, pois a natureza é fonte inesgotável de recursos, suas reservas são finitas e devem ser utilizadas de maneira racional, evitando o desperdício e considerando a reciclagem como processo vital (APROMAC, 2011).

A escola é o espaço social e o local onde o aluno dará sequência ao seu processo de socialização. O que nela se faz se diz e se valoriza, representa um exemplo daquilo que a sociedade deseja e aprova. Comportamentos ambientalmente corretos devem ser aprendidos na prática, no cotidiano da vida escolar, contribuindo para a formação de cidadãos responsáveis. Com isso os conteúdos ambientais permeando todas as disciplinas do currículo, e contextualizados com a realidade da comunidade, a escola ajudará o aluno a perceber a correlação dos fatos e a ter uma visão holística, ou seja, integral do mundo em que vive. Para isso a Educação Ambiental deve ser abordada de forma sistemática e transversal, em todos os níveis de ensino, assegurando a presença da dimensão ambiental de forma interdisciplinar nos currículos das diversas disciplinas e das atividades escolares Apromac (2011).

$\mathrm{Na}$ escola, as atividades envolvidas na horta permitem trabalhar os conteúdos de alimentação, nutrição e ecologia em diversas disciplinas (matemática, ciências, geografia, etc.). A horta, além de contribuir para a merenda escolar, proporciona a aquisição de bons hábitos alimentares, estímulo ao consumo de hortaliças e frutas, bem como resgate de hábitos regionais e locais. O hábito do consumo de hortaliças pode ser desenvolvido na escola com a participação dos alunos. Cria grande satisfação de poder aproveitar na alimentação escolar as hortaliças que os mesmos ajudaram a cultivar, sem falar que o aluno aprende o seu valor nutritivo, bem como seus benefícios para a sua saúde (FRICK, 2008).

Hoje as crianças e adolescentes das cidades normalmente passam o maior tempo de suas infâncias em frente aos meios tecnológicos assistindo ou manuseando-os, não tendo mais o contato com o meio ambiente. Desta forma se faz necessário que as escolas resgatem este contato, permitindo assim um relacionamento mútuo, e assim as hortas nas escolas possuem 
um papel importantíssimo, pois favorece um pressuposto dialético sobre a importância de uma alimentação saudável e equilibrada.

Com este projeto os alunos terão a satisfação de conciliar teoria de sala de aula com a prática na horta, interiorizando de forma prazerosa o que se aprendeu em sala de aula. Assim, terão experiências gratificantes e valiosas para vida, pois na concepção de Bassoul (1998), a saúde humana está ligada a uma boa alimentação, pois o estado nutricional é considerado bom quando todos os nutrientes essenciais forem fornecidos e utilizados para manter a saúde na sua plenitude. Esse estado é fundamental para as funções normais dos órgãos, para o crescimento e a reprodução, para eficiência no trabalho, assim como para a reparação de agressões que o organismo possa sofrer, com acidentes, infecções e cirurgias.

Este trabalho tem como objetivo principal levar o grupo estudantil a ter o conhecimento sobre a importância do alimento saudável e o cultivo de hortaliças para o complemento nutritivo da merenda escolar, estabelecendo uma relação entre teoria e prática no contato com o meio.

No desenvolvimento do trabalho outros objetivos foram estabelecidos, criando uma nova metodologia no ensino da educação ambiental, utilizando o sistema de produção orgânica de húmus com reaproveitamento de resíduos domiciliar, cascas de legumes, dejetos de animais, folhas de vegetais e gravetos, propondo uma discussão mais ampla sobre a ação do mesmo na educação ambiental com manejo de húmus e hortaliças, contribuindo na viabilização de projetos educacionais que integram meio ambiente, horta e compostagem na escola.

\section{MATERIAL E MÉTODOS}

O trabalho realizado trata-se de uma pesquisa descritiva que, segundo Vergara (2009), vai expor as diferenças de percepção ambiental sem emissão de julgamento. O mesmo foi realizado no período de março a dezembro de 2011, na escola Municipal Jardim das Flores, situada no bairro Jardim das Flores, à Rua Jasmim, s/nº, atendendo um grupo de 351 alunos no período matutino e vespertino. No desenvolvimento do projeto foi delimitada a construção de (06) seis canteiros. A distribuição do esterco e húmus deu-se da seguinte forma: O esterco na sua origem primitiva foi distribuído em média 20 litros por $\mathrm{m}^{2}$, auxiliando na descompactação dos canteiros, após a descompactação e incorporação do esterco primitivo deu-se a distribuição do húmus na proporção de 10 litros por m². 
Este projeto contou com a participação ativa de 25 estudantes do $5^{\circ}$ ano do ensino fundamental, em palestra educativa sobre educação ambiental, cultivo de horta domiciliar, utilização de resíduos orgânicos na compostagem, filme "ilha das flores" seguidas de perguntas norteadoras sobre o mesmo. Na sequencia houve a divisão aleatória desses alunos para a produção textual com o tema "A importância da compostagem para o meio ambiente" e confecções de quebra-cabeça sobre os textos produzidos.
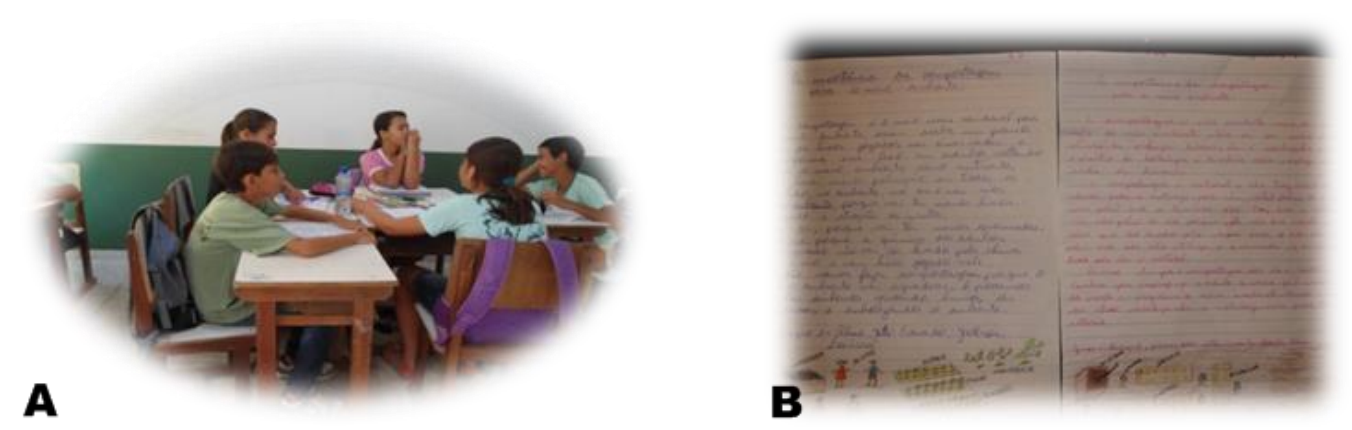

Figura 1. (A) Grupo reunido para a produção textual. (B) Textos produzidos Fonte: Elaborado pelo autor

$\mathrm{Na}$ sequencia foram feita entrevista com uma amostra representativa de 100 estudantes do ensino fundamental, para o plantio das hortaliças. O plantio seguiu critérios de maior aceitabilidade nos tipos de leguminosas e hortaliças.

$\mathrm{Na}$ confecção da compostagem cada estudante recebeu um recipiente plástico de $2 \mathrm{~kg}$ com tampa, toda semana no dia marcado traziam os resíduos orgânicos domiciliar e juntamente com os resíduos orgânicos do refeitório escolar, dava-se o início a confecção da compostagem.

\section{RESULTADOS E ANÁLISE}

Sempre ouvimos dizer que a escola é definida como meio que prepara para a vida, na verdade, a escola como instituição social, estabelece um vínculo ambíguo com a sociedade. Portanto o que devemos entender é que a tarefa da escola é zelar pelo desenvolvimento da sociedade e por isso, precisa criar indivíduos capazes de produzir riquezas, de criar, inventar, inovar e transformar. O trabalho com o resíduo orgânico na produção de húmus mostra a importância da ação pedagógica e muitas vezes revelam a desarmonia do ser humano com o meio ambiente, proporcionando no aluno a reflexão sobre o consumismo, estimulando 
atitudes preservacionistas e conscientes da interação do ser humano e natureza, tornando a ação pedagógica no trabalho cada vez mais rico e dinâmico (VIEIRA, 2012).

No que diz respeito a aceitação das hortaliças na merenda escolar, a que teve maior destaque, através das entrevistas realizadas foi o alface, seguido do couve e almeirão. Dentre as de menor destaque encontra-se a rúcula e o coentro, conforme mostra a figura 2.

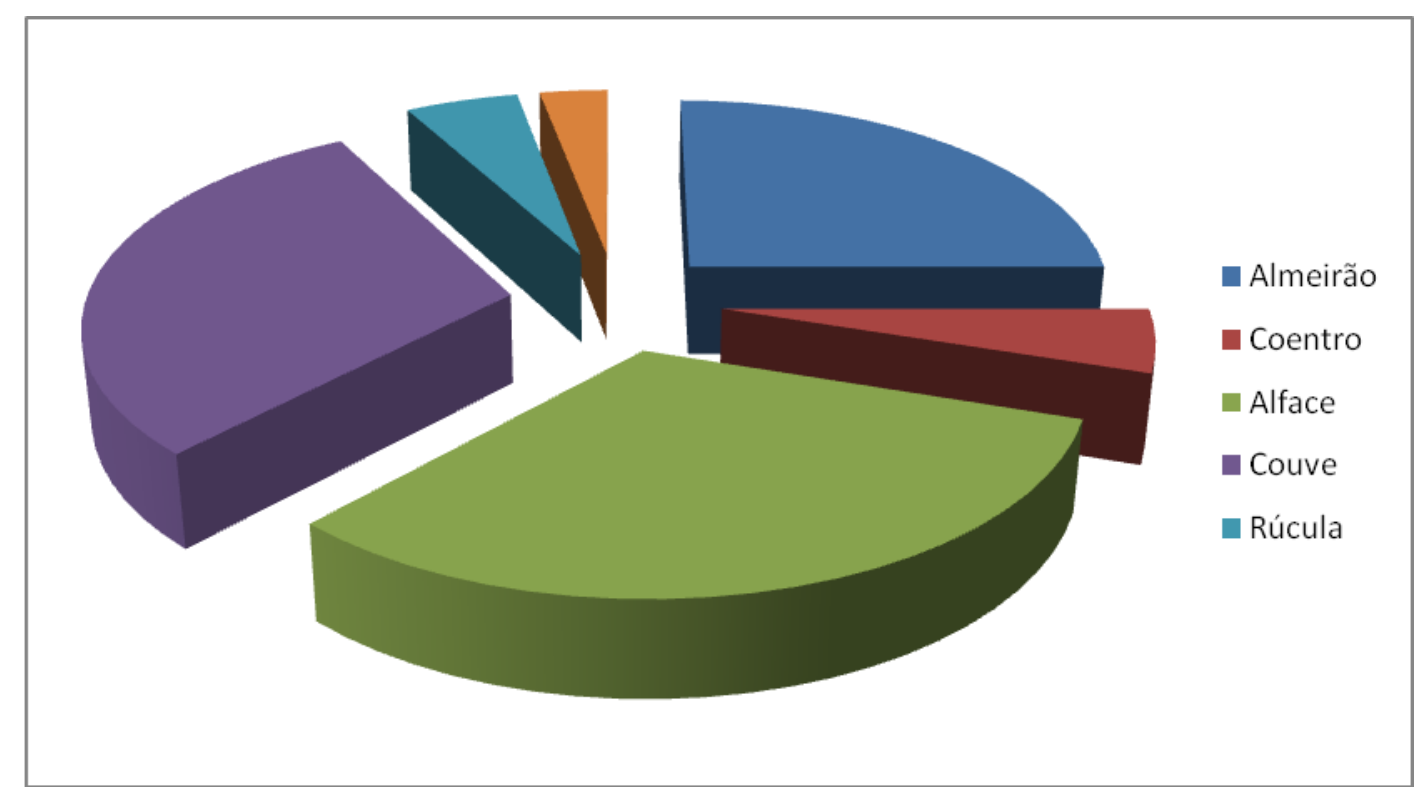

Figura 2. Verduras mais aceita na merenda escolar. Fonte: Elaborado pelo autor

Toda energia e vigor disponibilizado às células humanas provém dos alimentos que são produzidos e retirados do próprio planeta, da mesma forma toda a energia que necessitamos para realizar as mais diferentes atividades também é obtida no planeta: queima de combustíveis, usinas hidroelétricas, baterias, uso de energia solar, etc. Quanto mais matérias e energias necessitamos para a nossas atividades cotidianas, mais destruímos o ambiente natural. Por isso precisamos ficar muito atento às transformações que estamos provocando no planeta, devido as nossas atividades (SIGNORELLI, 1996). Percebe-se urgentemente a necessidade de desenvolver muitas palestras sobre a preservação e conservação do meio ambiente em: Associações, clubes de serviços, instituições de ensino entre outras, como nos relata Dias (2004, p.100): “acredito que a educação ambiental seja um processo por meio do qual as pessoas aprendam como funciona o ambiente, como dependemos dele, como o afetamos e como promovemos a sua sustentabilidade". 
Com a conscientização sobre a importância da horta domiciliar e a preservação do meio ambiente, mostrou ter uma consciência positiva sobre os diferentes tipos de verduras e leguminosas em seu dia a dia o seguinte número de alunos, conforme figura abaixo.

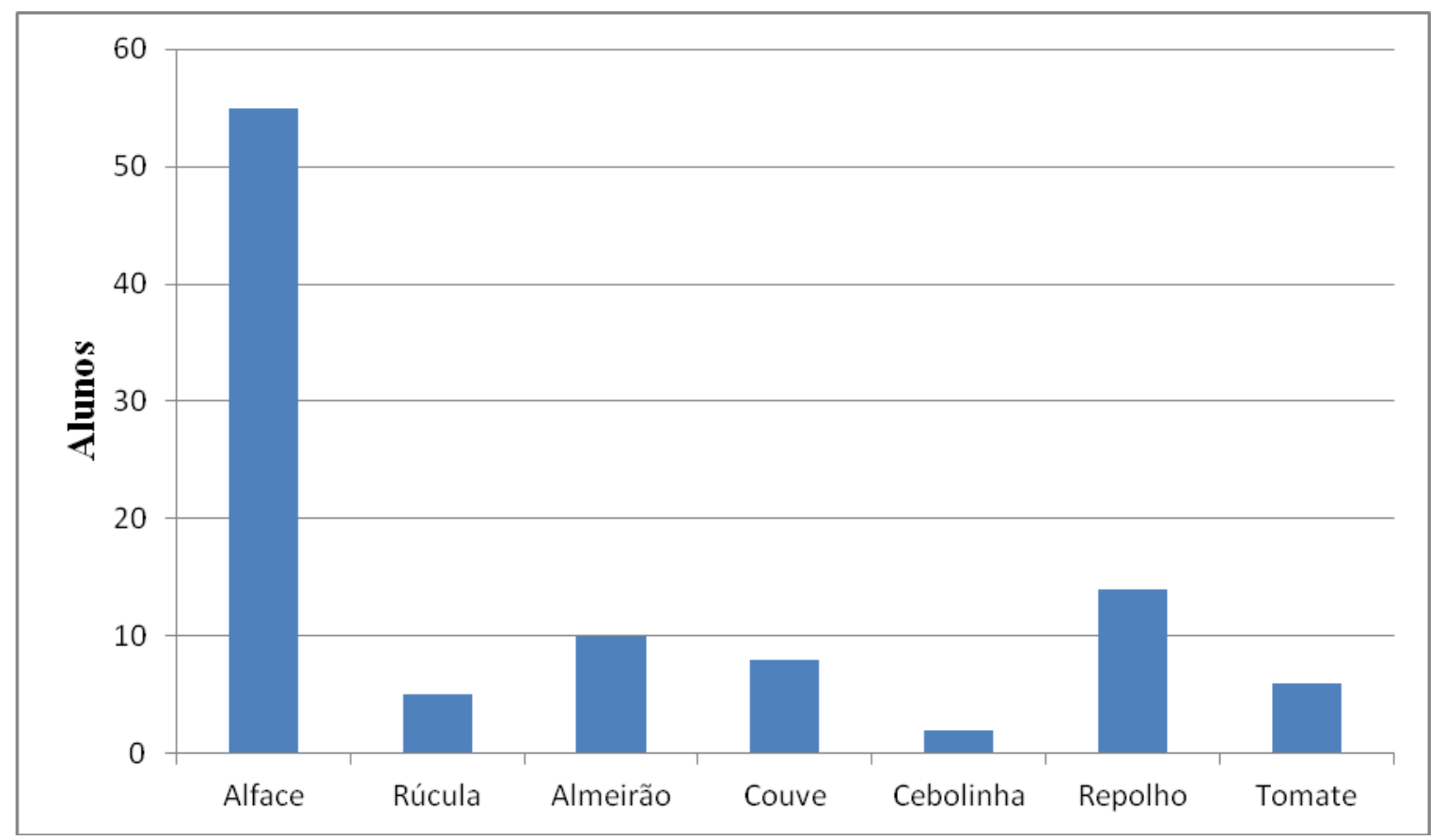

Figura 3. Verduras desejadas com frequência em sua alimentação domiciliar. Fonte: Elaborado pelo autor

A compostagem mostrou-se alinhada com os princípios da Alfabetização Ecológica, desenvolvendo nos alunos o interesse pelos processos naturais e busca de informações junto a professores e pais. Assim sendo, além de "plantar uma horta e usá-la como recurso para o preparo de refeições na escola é um momento perfeito para experimentar o pensamento sistêmico e os princípios da ecologia em ação" (CAPRA, 2005, p.26); considera-se que a prática da compostagem tem a mesma validade por restabelecer a conexão com os ciclos naturais (nascer, desenvolver-se, amadurecer e morrer) e impulsionador ao cultivo da horta por consequência.

Diante disso, percebe-se que $90 \%$ dos alunos que participaram do projeto, interiorizaram conhecimento sobre a importância da utilização dos resíduos orgânicos domiciliar na confecção da compostagem e apenas $10 \%$ dos alunos não demonstraram interesse em praticá-los domiciliarmente.

Segundo Teixeira (2002), a associação de resíduo orgânico deverá ser utilizada na proporção de $70 \%$ de material rico em hidratos de carbono (restos vegetais) e 30\% pobre em carbono (esterco de animais), mas rico em nitrogênio. Os materiais ricos em nitrogênio são de 
fácil decomposição e proporciona uma fonte de micronutrientes para o composto. O esterco além de fornecer nitrogênio é o material inoculante de bactérias e fungos.

Na opinião de Gomes e Pacheco (1988), os principais grupos de micro-organismos. que realizam a decomposição de matéria orgânica são bactérias e fungos. Os materiais inoculantes, como estercos, capins e folhas, restos de vegetais e tortas oleaginosas, são ricos nesses micro-organismos. Daí a necessidade de um destes materiais estarem presente no processo de compostagem. A compostagem trata-se de um processo de fermentação onde a presença do ar na massa em decomposição é indispensável. Para tanto, o material utilizado não deverá sofrer compactação excessiva e, periodicamente, deve ser revolvido. Ocorrendo fermentação na ausência do ar, haverá perda de nitrogênio, odores desagradáveis e problema de proliferação de moscas. O material em decomposição deverá estar sempre úmido, entre os limites de $30 \%$ e $70 \%$ de umidade. Valores menores que $30 \%$ impedem a fermentação e maiores que $70 \%$ expulsam o ar do ambiente. A melhor faixa de umidade está entre $40 \%$ e $60 \%$. O material deve mostrar-se úmido, sem, entretanto, deixar escorrer água quando prensado.

O trabalho dos micro-organismos para promover a decomposição da matéria orgânica resulta na liberação de calor, portanto aquecendo o meio. Segundo Gomes e Pacheco (1988), a melhor faixa de temperatura é de $60 \%$ a $70 \%$ o que, inclusive, contribui para a esterilização do material, provocando a morte de organismos que causam doenças às plantas e destruindo materiais propagativos de ervas daninhas (sementes, pedaços de caules, etc.). A constatação prática da temperatura desejável é feita mediante apalpamento, com as costas das mãos, em uma barra de ferro ou vara que se deixa fincada no material em decomposição, a uma profundidade mínima de $50 \mathrm{~cm}$. Deve-se senti-la quente, a $40 \mathrm{~cm}$ sem, entretanto ter necessidade de retirar a mão para não queimar.
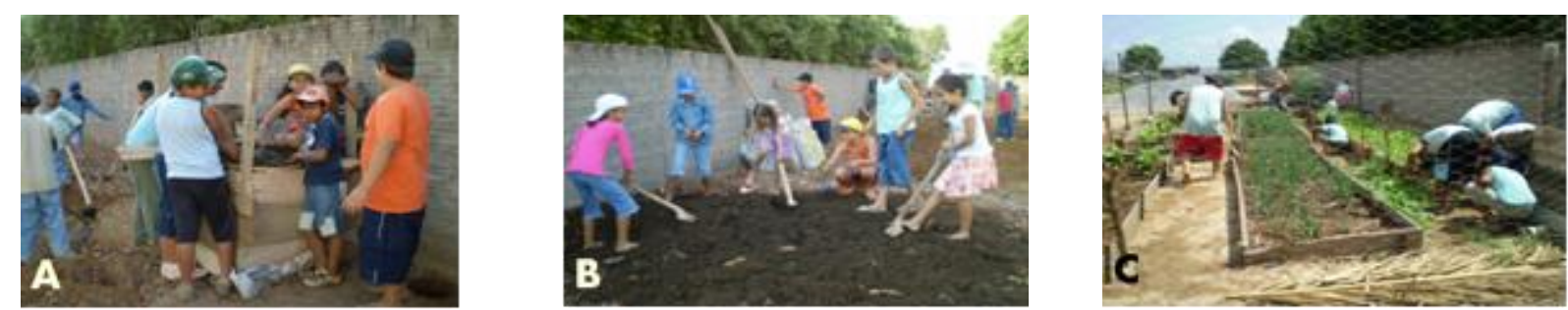

Figura 4. A) Caixote de compostagem, B) Distribuição de húmus na horta e C) Visita do grupo e manutenção dos canteiros. 


\section{CONSIDERAÇÕES FINAIS}

Em relação à aceitabilidade das hortaliças na merenda escolar, a que teve maior destaque, foi o alface, seguido do couve e almeirão. Dentre as de menor destaque encontra-se a rúcula e o coentro, percebeu-se uma maior aceitabilidade com verduras e leguminosas que possui sabor menos amargoso. Já na preferência de verduras e leguminosas em seu dia a dia domiciliar, ficou o alface, repolho e almeirão.

Notamos, que $90 \%$ dos educando que participaram do projeto, estão praticando a utilização dos resíduos domésticos e outros resíduos na confecção da compostagem domiciliar, ficando constatado que essa associação de resíduo orgânico é essencial no processo da decomposição, pois favorece as ações dos fungos e bactérias na produção de húmus, contribuindo na redução dos resíduos domésticos, beneficiando o meio ambiente.

\section{REFERÊNCIAS}

APROMAC - Associação de proteção ao meio ambiente de Cianorte. Projeto de Educação Ambiental Parque Cinturão Verde de Cianorte - Paraná 2011. Disponível em: http://www.apromac.org.br. Acesso em: 31 mar. 2012.

BASSOUL, E. B. P. Nutrição e Dietética. Editora Senac Nacional, São Paulo, 1998.

CAPRA, F. Alfabetização Ecológica: o desafio para o século 21. In: Meio ambiente no século 21: 21 especialistas falam da questão ambiental nas suas áreas de conhecimento/coordenação de André Trigueiro: prefácio de Marina Silva. Campinas: Armazém do Ipê. Autores Associados. 2005. 367 p.

DIAS, G. F. Educação Ambiental: princípios e práticas. São Paulo: Gaia, 2004.

FRICK, K. P. Proposta da atividade pedagógica de complementação curricular. 2008.

GOMES, W. R.; PACHECO, E. Composto orgânico. Lavras: Escola Superior de Agricultura de Lavras, Boletim Técnico 11, 1988, 11 p.

SIGNORELLI, V. Conversa de professor: Ciências. Brasília, Ministério da Educação e do Desporto, Secretaria de Educação à Distância, Caderno TV Escola, 1996, 47p. 
TEIXEIRA, R. F. F. Compostagem. In: HAMMES, V. S. (Org) Educação ambiental para o desenvolvimento sustentável. Brasília: Embrapa Informação Tecnológica, v.5, p.1201232002 ,.

VERGARA, S. C. Projetos e Relatórios de pesquisa em administração. São Paulo: Atlas, 2009.

VIEIRA, E. J. A reciclagem como instrumento de ensino. Disponível em: http://www.pedagogiaaopedaletra.com/posts/monografia-a-reciclagem-como-instrumento-deensino/. Acesso em: 25 set. 2012. 